\title{
CHANGING THE CULTURE OF COASTAL, OCEAN, AND MARINE SCIENCES STRATEGIES FOR INDIVIDUAL AND COLLECTIVE ACTIONS
}

By Mona Behl, Sharon Cooper, Corey Garza, Sarah E. Kolesar, Sonya Legg, Jonathan C. Lewis, Lisa White, and Brandon Jones

\begin{abstract}
Geoscience is plagued with structural and systemic barriers that prevent people of historically excluded groups from fully participating in, contributing to, and accruing the benefits of geosciences. A change in the culture of our learning and working environments is required to dismantle barriers and promote belonging, accessibility, justice, equity, diversity, and inclusion in our field. Inspired by a session organized at the 2020 Ocean Sciences Meeting, the goal of this paper is to provide a consolidated summary of a few innovative, broadening participation initiatives that are being led by various stakeholders in academia and research sectors (e.g., students, faculty, administrative leaders) at different institutional levels (e.g., universities, professional societies). The authors hope that the strategies outlined in this paper will inspire the coastal, ocean, and marine science community to take individual and collective actions that lead to a positive culture change.
\end{abstract}

\section{INTRODUCTION}

Over the past few years, abundant news articles reporting violence against communities of color in America have spurred members of the geoscience community to pay much-needed attention to promoting belonging, accessibility, justice, equity, diversity, and inclusion in our disciplines, including in the coastal, ocean, and marine sciences (e.g., see antiracism initiatives No Time for Silence, Call for a Robust Anti-Racism Plan for The Geosciences, Unlearning Racism in Geoscience, and Black in Marine Science, among others). For years, many wellintentioned programs have invested time and resources to attract students from historically excluded groups into the coastal, ocean, and marine (COM) science workforce, with limited retention success. It has become increasingly clear that recruitment is not enough. What is urgently needed is a change in the culture that includes systematic eradication of exist- ing paradigms and models that have perpetuated racism, inequities, and injustices in higher education. Bold new paradigms and models are needed to create working and learning climates where all can thrive, both personally and professionally.

To truly take an all-hands-on-deck approach to solving the enormous environmental problems humanity now faces, the COM science enterprise needs to critically examine and evaluate the effectiveness of its traditional working and learning practices. Why would anyone want to stay in a discipline that is disrespectful, toxic, and unwelcoming? How do we expect to retain people if they don't see others with similar backgrounds and experiences in positions of leadership and power? How can people pursue science in environments that perpetuate harassment, discrimination, and misconduct? We will all benefit by creating a scientific and professional culture that offers its workforce exciting, financially viable, and fulfilling careers replete with purpose and comradeship. We challenge all those engaged in the COM science enterprise, and in particular, the leadership of these disciplines, to reimagine the culture of our working and learning environments. We encourage leaders to operationalize new frameworks to improve the culture of COM sciences so that all people entering our workforce feel welcomed, are able to bring their whole selves to their places of work, and truly reach their full potentials while advancing science.

Culture change can happen only when we inculcate and model respect for individual cultures and identities, open ourselves to integrating traditional and indigenous ways of knowing with western ways of doing science, remove barriers that prevent people from participating fully in COM science disciplines, and develop inclusive pedagogical practices. While developing a culture that welcomes and respects diverse identities and perspectives is the right thing to do for its own sake, it also benefits science: diverse teams are more productive and more likely to develop novel solutions to problems than homogeneous research teams (e.g., see Cheruvelil et al., 2014; Freeman and Huang, 2014; Hofstra et al., 2020). Baseball offers an interesting example of how diversity can transform an entire field. The story of Jackie Robinson is well known to generations of baseball fans (Simon, 2002). As the first African American to play major league 
baseball, his inclusion not only diversified the game but also transformed both how the game is played and the essential skill sets found in modern major league baseball teams. As part of his inclusion into the game, Robinson was supported by Branch Rickey, the general manager of the Dodgers, who was willing to not only sign him to a contract but also to create an environment that allowed him to thrive as a baseball player. It was Rickey's understanding that supporting Robinson's talents would further the overall success of the Dodgers that provided a model for how modern major league baseball teams operate. Today, major league baseball players are a diverse collection of individuals from around the world whose talents come together in ways that were not possible in previous generations. Corporations, such as IBM, adopt this very model in order to recruit and diversify the modern computer science workforce and to help the next generation flourish in computer sciences (Childs, 2005). As we look ahead to the emerging research challenges of the twenty-first century, the COM science enterprise will need its own Branch Rickeys and innovative models of engagement and retention to help support a new generation of scientists and leaders.

This article was inspired by a session at the 2020 Ocean Sciences Meeting in San Diego, California, entitled, "Changing the Culture: Preparing a Diverse and Inclusive Ocean Sciences Workforce." Our goal is to offer a selection of strategies for promoting belonging, accessibility, justice, equity, diversity, and inclusion (BE A JEDI) in the COM sciences, acknowledging that action needs to be taken at multiple levels (i.e., individual, institutional, and structural). Examples of efforts included here range from student to administrative levels. These examples are not meant to be exhaustive; instead, we use them to highlight actionable strategies for various professional levels in academia. Readers are strongly encouraged to review additional literature outlining needs and actionable recommendations for broadening participation in geo- sciences by key stakeholders in academia (Petcovic et al., 2016). Some groups that have faced discrimination or have been historically excluded from the COM science enterprise include non-white people, members of the LGBTQA+ community (encompassing the full spectrum of sexuality and gender), individuals from socioeconomically disadvantaged backgrounds, and people with disabilities. The intended audiences for this article include faculty, administrators, and professionals working in academic, public, and private sectors. The author team includes scientists and professionals who are engaged in developing and enhancing initiatives to broaden participation in the geosciences. Several members of the author team are representative of historically excluded groups referenced in this paper.

\section{UNDERSTANDING THE BE A JEDI BASELINE}

Over the past decade, reports developed by the National Science Board (NSB, 2020), the National Academies, and the President's Council of Advisors on Science and Technology (PCAST, 2020) have documented the substantial role played by the science, technology, engineering, and mathematics (STEM) disciplines as drivers of American innovation, prosperity, and global competitiveness. These reports have also noted that the "need for STEM knowledge extends to all Americans," due to the growing role of STEM in informing personal choices and public decisions. Yet, in spite of continually growing demand for STEM expertise and literacy, fewer American students are pursuing advanced degrees and careers in STEM disciplines, and insufficient progress is being made in engaging the full diversity of the nation's potential talent pool for those fields (Wang, 2013; Smith, 2020).

The Status of the Geoscience Workforce 2018 report (Wilson, 2019) and related efforts assess the educational and employment landscape within the geosciences and document clear evidence of a deficit in workforce training (Zeigler and Camarota, 2014; Gonzales and Keane 2020a, 2020b). The US Bureau of Labor Statistics estimates a higher than average growth rate in demand for geoscientists, with a $4.9 \%$ increase in jobs between 2019 and 2029 (Gonzales and Keane, 2020a), while the American Geosciences Institute (AGI) predicts that production of new geoscientists at current rates will be insufficient, resulting in a shortfall of $\sim 118,000$ geoscientists by the year 2026 .

Improving efforts to retain students from groups that have historically been discriminated against by or excluded from the geosciences community is important because even though these students will soon be the majority of college-age students in undergraduate programs (Starks and Matthaeus, 2018), the geoscience workforce continues to lag behind other STEM fields in creating a diverse community of researchers, scholars, practitioners, and entrepreneurs (Bernard and Cooperdock, 2018). The participation of individuals from these groups in the geosciences has been up to $25 \%$ lower than whole population demographic trends since 2007 (Gonzales and Keane, 2020b), despite the benefits their participation would bring to the field. Beane et al. (2021) explored in detail race and ethnicity trends for students receiving geoscience bachelor's degrees in the United States over the past 20 years. While they reported some promising trends, only a few institutions drive the increase in diversity of geoscience bachelor's degree recipients, and the biggest influence on the diversity of those receiving geoscience degrees is both regional demographics and institutional student demographics. Diversity promotes innovation, strengthens the community's ability to tackle complex geoscience research problems, and engenders widespread public literacy about the Earth system, science, and services (Russell et al. 2007; NRC, 2011, 2012; Thiry et al., 2012; Atchison and Gilley, 2015). Prior investments designed to broaden participation have mostly focused on recruitment of individuals from historically excluded groups into the geosciences (Gilligan and 
Ebanks, 2016; Johnson et al., 2016), but not on issues related to retention and success (Starks and Mattheaus, 2018). A lack of a sense of belonging, racism, sexism, cultural differences, and imposter syndrome are a few of the many barriers that prevent people from fully participating in geosciences and other STEM disciplines (Anderson and Kim, 2006; NASEM, 2016). Additionally, "one-size-fits-all" approaches (e.g., increased recruitment) have proven to be insufficient in addressing these challenges.

Because multiple factors contribute to the lack of diversity in geosciences, there must also be multiple corrective approaches (O'Connell and Holmes, 2011; Starks and Matthaeus, 2018) that can be deployed to change the culture of our learning and working environments. In the academic context, specific strategies need to be identified to attract and retain students, researchers, and faculty from historically excluded groups so they can operate with a strong sense of belonging in their respective areas of teaching, research, and leadership and service (Hurtado et al., 2010; NRC, 2011; Chang et al., 2014; Bernard and Cooperdock, 2018; Starks and Matthaeus, 2018; NASEM, 2019).

\section{BE A JEDI RECRUITMENT PATHWAYS}

Students are attracted to geosciences for a variety of reasons, including love of the outdoors, family influences, positive $\mathrm{K}-12$ and undergraduate experiences, and perceived societal relevance of the geosciences (Holmes and O'Connell, 2005). However, these "attractors" may not resonate with the social and cultural experiences of individuals from historically excluded groups, nor do they reflect the descriptions of all geoscience careers. Intentional, sustained, and measurable actions are needed to produce a workforce that more closely resembles the population that the COM sciences aim to serve. Below, we summarize a variety of different recruitment actions, along with successful examples, that institutions can take to improve participation of historically excluded groups in the COM sciences. Note that websites for programs and organizations mentioned below are listed in the Resources table on this page.

\section{Engage Families and Community}

In order to consider opportunities in the COM sciences, individuals from groups that have been historically excluded in STEM need to first know that these opportunities exist. Communication about opportunities can be initiated by engaging students' families and communities in hands-on learning. Evidence suggests that families can play an important motivational role in sparking and sustaining interest in STEM careers (Caspe et al., 2018). The Ocean Discovery Institute (ODI) in San Diego, California, sponsors a Scientistin-Residence Program that allows scientists to spend periods from weeks to months at ODI, providing mentorship to students, and improving access and exposure to ocean science
RESOURCES

Ambassadors for STEM Training to Enhance Participation (A-STEP) https://astep.berkeley.edu/

Black in Marine Science (BIMS)

https://www.blackinmarinescience.org/

Black Women in Ecology, Evolution, and Marine Science (BWEEMS)

https://www.bweems.org/post/black-women-in-ecologyevolution-and-marine-science-we-do-exist

Call for a Robust Anti-Racism Plan for the Geosciences

https://www.change.org/p/geoscientists-call-for-a-robustanti-racism-plan-for-the-geosciences

Early Career Leadership Academy (ECLA)

https://www.ametsoc.org/index.cfm/ams/education-careers/ early-career-leadership-academy/

Embodied Physics (EP) -

STEM Learning for Under-Represented Youth

https://www.terc.edu/projects/embodied-physics/

Equity, Diversity, and Inclusion (EDI) at Scripps Institution of Oceanography https://scripps.ucsd.edu/diversity

Geopaths Catalina Scholars Program (GCSP)

https://www.msmu.edu/resources-culture/iuse/

Hālau Ola Honua Oceanography Summer Bridge program (SBP)

https://sites.google.com/a/hawaii.edu/halau-ola-honua/ oceanography-summer-bridge

Louis Stokes Minority Alliance Program (LSMAP)

https://studentaffairs.oregonstate.edu/LSAMP

Mentoring Physical Oceanography Women to Increase Retention (MPOWIR)

https://mpowir.org/

National Association for Black Geoscientists (NABG)

https://www.americangeosciences.org/society/ national-association-black-geoscientists

\section{No Time for Silence}

https://notimeforsilence.org/

Ocean Discovery Institute (ODI)

https://oceandiscoveryinstitute.org/

Ocean Womxn

https://oceanwomxn.co.za/

Optimizing the Intern Experience (OIE)

https://www.usgs.gov/center-news/ optimizing-intern-experience-a-woods-hole-workshop

Oregon State University College of Earth, Ocean, and

Atmospheric Science "Unpacking Diversity” (UD)

https://unpackingdiversity.wixsite.com/ceoas

Salish Sea Research Center (SSRC)

https://www.salishsearesearchcenter.com/

Science, Technology, Engineering, and Math Student Experiences Aboard Ships (STEMSEAS) https://mlp.Ideo.columbia.edu/stemseas/

Society for Advancing Chicanos/Hispanics and Native Americans in Science (SACNAS) https://www.sacnas.org/

University of South Carolina's Green Quad (GQ)

https://sc.edu/about/offices_and_divisions/housing/green_quad/

Unlearning Racism in Geosciences (URGE) https://urgeoscience.org/ 
opportunities. Inclusion of families in the scientific learning experience of students is integral to the success of this program. Further, ODI incorporates multiple learning strategies for English language learners. The NSF-funded Ambassadors for STEM Training to Enhance Participation is another program designed to bridge the gap between scientists and diverse communities, training science students to communicate their learning experiences in Earth and ocean sciences, and their enthusiasm, to their wider communities.

\section{Integrate Arts and}

Humanities in STEM

An emerging body of evidence suggests that integration of arts and humanities in STEM fields is associated with positive learning outcomes that help students enter the workforce and pursue careers in these fields (NASEM, 2018a). Innovative STEM programs like Embodied Physics: STEM Learning for UnderRepresented Youth (led by the Woods Hole Oceanographic Institution in collaboration with community-based dance centers in the Boston area) use informal art-based learning environmentsin this case, community dance studiosto engage African American and Latinx high school students to learn key ideas in physics. Using crossover teaching techniques, choreographers teach science and scientists teach choreography.

\section{Leverage Scientific and} Professional Societies

One of the many strategies that can be used to recruit students into COM science opportunities is broadly publicizing opportunities through, for example, professional societies and affinity groups that primarily support individuals from historically excluded groups. Such organizations include Society for Advancing Chicanos/Hispanics and Native Americans in Science; National Association for Black Geoscientists; Black Women in Ecology, Evolution, and Marine Science; and Black in Marine Science. Local chapters of these societies, or other campus-based groups such as NSF's Louis Stokes Minority Alliance Program, provide effective resources for reaching students and cultivating relationships with mentors. Instead of waiting for applicants to apply, proactive effort should be invested in outreach to inform historically excluded individuals and communities about opportunities in COM sciences, develop relationships, answer questions, and provide guidance and support through the application process.

\section{Collaborate with \\ Community Colleges}

Community colleges are an often overlooked but essential component of our education system. In 2020, of the nearly 12 million students enrolled in community colleges, $26 \%$ were Hispanic, 13\% Black, 6\% Asian/Pacific Islander, and $1 \%$ Native American, and 4\% represented two or more races (American Association of Community Colleges, 2020). Twentynine percent of students enrolled in community colleges were first generation and $20 \%$ had physical or cognitive disabilities (American Association of Community Colleges, 2020). Carefully designed summer bridge programs can often enhance students' interest, provide them with support, and establish academic acculturation. The Hālau Ola Honua Oceanography Summer Bridge program led by University of Hawai'i Mānoa's School of Ocean and Earth Science and Technology provides one such opportunity for Native Hawaiian students. During a six-week residential summer course, students not only study the biology, physics, and chemistry of the ocean but also participate in field experiences that integrate local knowledge and community engagement. To ease the financial pressures faced by Native Hawaiian students, the program offers free lodging, stipends, and college credits.

\section{Build and Strengthen Partnerships} with Minority-Serving Institutions

Minority-serving institutions (MSIs), including two-year and four-year, public and private, rural, urban, and suburban institutions, are another underutilized resource for strengthening, expanding, and diversifying COM science fields (NASEM, 2019). MSIs include students who not only vary in race and ethnicity but also in terms of age and enrollment intensity (i.e., full time and part time). A partnership between the Geopaths Catalina Scholars Program led by Mount Saint Mary's University, a minority-serving women's college, and the University of Southern California, a research intensive (R1) university, broadens participation through a cross-campus experiential partnership. The program engages annual cohorts of students in research-intensive experiences, professional development workshops, and opportunities to present at conferences.

\section{Use Cohort-Focused and Place- \\ Based Education Approaches}

Cohort-focused undergraduate research experiences, including those that impart culturally relevant education to students, can be transformative in recruiting and retaining diverse students in geosciences (Karsten, 2019). Ladson-Billings (1994) defined culturally relevant pedagogy as one "that empowers students intellectually, socially, emotionally, and politically using cultural referents to impart knowledge, skills, and attitudes" (pp. 16-17). Additionally, the importance of placebased education in science is well documented (e.g., Sarkar et al., 2008; Coker, 2017). Place-based education builds directly on what students are already familiar with, connects them to other disciplines and ways of knowing (e.g., traditional and local knowledge), and provides relevance and context to scientific concepts that might otherwise seem abstract to them. The Salish Sea Research Center at the Northwest Indian College is one example of a program that fosters respect for indigenous knowledge by providing culturally inclusive research experiences for students at tribal colleges. Through mentorship provided by faculty, minority graduate students, and tribal community members, students engage in research 
projects that incorporate elements of food sovereignty, resource management, and social justice.

Another program, STEM Student Experiences Aboard Ships (STEMSEAS; Cooper and Lewis, 2017), provides shipbased, six- to 10-day exploratory experiences for undergraduates from diverse backgrounds. Since 2016, STEMSEAS has provided $>120$ undergraduates with at-sea experiences. Cohorts commonly have transformative experiences that foster deep intra-cohort bonds and also substantial growth of science mentor supportive culture that fosters cooperation and collaboration, provides a feeling of appreciation for the work that people do, and cultivates a sense of belonging. While necessary for retention, culture change can be challenging as it requires changes in closely held values, beliefs, and assumptions, among other things. Ways of addressing this challenge include acknowledging and understanding the unique needs of people from historically excluded groups; having honest discussions around uncomfortable topics such as racism, sexism, and ableism; reforming

\section{Build Inclusive Work Culture}

A geoscience-wide example of group learning is the Unlearning Racism in Geosciences program, which brought together thousands of students, researchers, and faculty from many different academic and research institutions to study a geoscience-focused anti-racist curriculum online (freely available to all interested readers). Another example of an initiative to generate a more inclusive campus culture, in response to advocacy from graduate students, is the creation of a Director of Diversity Initiatives

\section{A change in the culture of our learning and working}

environments is required to dismantle barriers and promote belonging, accessibility, justice, equity, diversity, and inclusion in our field.

networks. Simultaneously, STEMSEAS makes a deliberate effort to expose students to a variety of careers in the geosciences, not solely academic tracks. Lastly, a partnership between university housing and the School of Earth, Ocean, and Environment, the University of South Carolina's Green Quad is an example of a sustainable living-learning community that connects students to each other while building a community in which students incorporate sustainability into their knowledge and habits. The program also links students to onsite advisors who provide individualized academic and career counseling to achieve personal and professional goals. There is a real need for exposure to the wide diversity of interesting, well-paying, and fulfilling jobs that exist in COM fields, but are not widely known.

\section{BE A JEDI RETENTION PRACTICES}

As mentioned in the introduction, recruitment alone is not sufficient. To retain a diverse workforce, the COM science enterprise must create a truly existing models/mechanisms/policies for assessment, evaluation, and reward; and providing resources and support that are essential for people to work and thrive. Examples of such activities realized at individual and institutional levels are offered below.

\section{Acknowledge Lived Experiences}

Discussions during a 2019 Woods Hole workshop on Optimizing the Intern Experience highlighted the isolation and discrimination experienced by interns, and the need for community members to learn to acknowledge, and understand the challenges faced by scientists from historically excluded groups. The movie Can We Talk? Difficult Conversations with Underrepresented People of Color: Sense of Belonging and Obstacles to STEM Fields (https://www. kendallmooredocfilms.com/), featured at many national meetings in the past year, has provided an opportunity for many in the geosciences community to learn about and understand experiences of community members from marginalized groups. at Scripps Institution of Oceanography, along with Community Engagement Fellows appointed from among the graduate students. Together, these individuals are working to create a greater sense of community and inclusion for all students.

\section{Lead Positive Change}

The provision of financial support and professional resources has been explicitly recognized by the Ocean Womxn program at University of Cape Town as essential to addressing the needs of its recruits. Honest conversations on uncomfortable topics are needed, for example as conducted in the Oregon State University's College of Earth, Ocean, and Atmospheric Science "Unpacking Diversity" discussion series. These facilitated discussions use published material as starting points for exploring topics ranging from "Institutional Discrimination in Higher Education" to "Microaggressions on Campus." This initiative was organized by graduate students, but discussions are open to all in the college, and a significant number of faculty as well as students attend, increasing the network 
of those educated about and engaged in diversity-related activities. The inclusion of senior faculty in these discussions is vital if discussion is to lead to action, and institutions should provide incentives to encourage this engagement. In this particular case, the discussions led to a document outlining a list of recommended actions for culture change in the college.

\section{Reimagine the Promotion}

and Tenure Process

Education and awareness comprise only the beginning of the process to create culture change. All traditional policies and procedures for hiring, evaluating, rewarding, and promoting scientists, both within and outside academia, need to be critically reexamined and reevaluated, including selection criteria, ways in which resources and opportunities are distributed, ways in which productivity is defined and rewarded, and achievement of outcomes. In academia, the tenure and promotion processes measure research productivity based on traditional criteria, including awards and grant funding, publications, citations, degrees conferred, and credit hours that students complete. However, research suggests that people of color are often engaged in activities that are unrecognized, unrewarded, and draw time away from research (Griffin, 2019). Faculty of color also often carry heavy teaching burdens, engage in service work, and are targeted to serve on diversity, equity, and inclusion (DEI) committeesactivities that are very important but that do not fit under the traditional notions of "rigorous scholarship," and are considered unworthy of recognition for reward or promotion. COM sciences could draw inspiration from strategies being used in other disciplines to promote diversity in academic departments (Griffin, 2019; Wingfield, 2020).

\section{Provide Mentorship and Build Cohorts}

The COM science enterprise needs to examine who is included in our collaborative and mentoring networks, who we share our intellectual and cultural expertise with, who we champion, and who we are missing. An example of communityled initiatives to expand mentoring networks is Mentoring Physical Oceanography Women to Increase Retention, a decade-long program designed to improve access to mentoring for women in physical oceanography, which has seen considerable success in the advancement of women into faculty and long-term research positions. Developing similar discipline-specific mentoring networks focused on oceanographers from other historically excluded groups may enhance access to collaborations and resources, as well as improve a sense of belonging in the community. The American Meteorological Society's Early Career Leadership Academy is another example of a program specifically designed to provide leadership skills, increase access to mentoring, and build a community of diverse early career professionals working in the weather, water, and climate science professions. This program has included scientists from historically excluded groups in the leadership structure right from the beginning, ensuring they have a say in the design and decision-making processes. Both programs focus on the early career stage of an individual's scientific or professional journey, where networks and collaborations are crucial to progress and career advancement.

\section{Foster Institutional}

\section{Partnerships with MSIs}

Meaningful institutional partnerships between R1 universities and MSIs, which serve as incubators for a diverse scientific workforce and talent pool (NASEM, 2019), can lead to shared governance of research projects and leveraging of resources in mutually beneficial ways, thus advancing an overarching vision of addressing big scientific challenges through mutual respect and recognition. All too often though, faculty at R1 universities partner with those at MSIs as an opportunity for completing the outreach or broader impacts requirements on grants, ignoring the research talent that exists in these universities (NAS, NAE, and IM, 2011; Garza, 2021). Authentic and respectful collaborations are needed, including more equitable distribution of funds, so that science endeavors can benefit from the additional perspectives of researchers and students at MSIs, Historically Black Colleges and Universities (HBCUs), and tribal colleges and universities. A truly synergistic approach would be to initiate conversations about collaborative research proposals with MSIs from the outset. Through their merit review processes, funding agencies can also identify proposals that are clearly "adding on" collaborators from MSIs, focusing on diversity simply to bolster the appearance of broader impacts without meaningfully engaging them in research.

\section{Leverage Professional}

\section{Societies and Institutions}

The role of professional and scientific societies in changing the culture of the COM science community cannot be overstated. In addition to serving as the "voice" of the research enterprise and providing professional development opportunities, these societies set the standards for responsible and ethical professional and scientific conduct, and advance our mutual understanding of disciplinary methods, languages, and cultures (NAE, 2018). Similar to actions called out in a few recent antiracism initiatives (e.g., No Time for Silence, Call for a Robust AntiRacism Plan for the Geosciences), professional and scientific societies, such as the Association for the Sciences of Limnology and Oceanography (ASLO) and The Oceanography Society, must reexamine their institutional practices to eradicate biases and prevent racial and sexual harassment (NRC, 2013; NASEM 2018b, 2020). A recent study of editorial appointments at ASLO journals highlights the appointment of men to associate editor positions at earlier career stages than women (Poulson-Ellestad et al., 2020). Editorial appointments are one example of an opportunity provided to scientists 
with subjective criteria that may favor affinity biases. Societies need to conduct audits of these and other practices to identify existing biases, and then implement actions to eliminate them. Additionally, initiatives such as the Coriolis Reception and the Color of Weather Reception at the AMS annual meeting provide space for members, friends, and allies of the LGBTQ+ and Black and African American communities to mentor, network, and connect with individuals who share common professional and personal interests. Recent efforts spearheaded by early-career scientists suggest that the American Geophysical Union (AGU) and ASLO are taking a leadership role in recognizing the need for more inclusive meeting spaces. In particular, to support LGBTQ+ scientists, AGU has made AGQ an official meeting feature, and the Ocean Sciences Meeting has offered the Rainbow Reception.

\section{CONCLUSION}

Robust action is required at multiple levels (i.e., individual, institutional, and structural) to improve the recruitment, participation, and retention of people

from historically excluded groups in the COM science enterprise. This paper features only a few of many strategies for individual and collective action that can bring about meaningful and sincere culture change (Table 1$)$. The relatively small number of successful strategies summarized in this paper is evidence that much more work needs to be done to prepare a diverse and inclusive COM science workforce. Addressing the most compelling challenges of the twenty-first century and facilitating new avenues of discovery and innovation will require nurturing the careers of people from historically marginalized groups and recognizing their perspectives in ways that have not previously been fully appreciated and integrated. We exhort our colleagues to improve the culture of COM sciences by moving past the learning and reading stage to deliberately designing and implementing strategies that meaningfully engage people and communities as equal partners in the scientific research process-so the benefits of our exciting, fulfilling, and increasingly important science can be contributed to and enjoyed by all. @

TABLE 1. Strategies for individual and collective action.

\begin{tabular}{|c|c|c|}
\hline & STRATECIES & $\begin{array}{c}\text { SCALE OF } \\
\text { ACTION }\end{array}$ \\
\hline \multirow{7}{*}{ 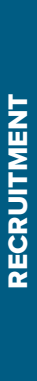 } & Engage Families and Community & Individual \\
\hline & Integrate Arts and Humanities in STEM & Individual \\
\hline & Leverage Scientific and Professional Societies & Collective \\
\hline & Collaborate with Community Colleges & Collective \\
\hline & Build and Strengthen Partnerships with Minority-Serving Institutions & Collective \\
\hline & Implement Culturally Relevant Pedagogy & Collective \\
\hline & Use Cohort-Focused and Place-Based Education Approaches & Collective \\
\hline \multirow{7}{*}{$\frac{z}{\frac{z}{5}}$} & Acknowledge Lived Experiences & Individual \\
\hline & Build Inclusive Work Culture & Individual \\
\hline & Lead Positive Change & Individual \\
\hline & Reimagine the Promotion and Tenure Process & Collective \\
\hline & Provide Mentorship and Build Cohorts & Collective \\
\hline & Foster Partnerships with Minority-Serving Institutions & Collective \\
\hline & Leverage Professional Societies and Institutions & Collective \\
\hline
\end{tabular}

\section{REFERENCES}

American Association of Community Colleges. Fast Facts, 2 pp., https://www.aacc.nche.edu/ research-trends/fast-facts/.

Anderson, E., and D. Kim. 2006. Increasing the Success of Minority Students in Science and Technology. American Council on Education, Washington, DC, 25 pp., https://www.acenet. edu/news-room/Documents/Increasing-theSuccess-of-Minority-Students-in-Science-andTechnology-2006.pdf.

Atchison, C.L., and B.H. Gilley. 2015. Geology for everyone: Making the field accessible. Earth Magazine, https://www.earthmagazine.org/article/ geology-everyone-making-field-accessible.

Beane, R.J., E.M. Baer, R. Lockwood, R.H. Macdonald, J.R. McDaris, V.R. Morris, I.J. Villalobos, and L.D. White. 2021. Uneven increases in racial diversity of US geoscience undergraduates. Communications Earth \& Environment 2(1):1-4, https://doi.org/10.1038/s43247-021-00196-6.

Bernard, R.E., and E.H.G. Cooperdock. 2018. No progress on diversity in 40 years. Nature Geoscience 11(5):292-295, https://doi.org/10.1038/ s41561-018-0116-6.

Caspe, M., T.A. Woods, and J. Kennedy, eds. 2018. Promising Practices for Engaging Families in STEM Learning. Information Age Publishing Inc., Charlotte, NC.

Chang, M.J., J. Sharkness, S. Hurtado, and C.B. Newman. 2014. What matters in college for retaining aspiring scientists and engineers from underrepresented racial groups. Journal of Research in Science Teaching 51(5):555-580, https://doi.org/10.1002/tea.21146.

Cheruvelil, K.S., P.A. Soranno, K.C. Weathers, P.C. Hanson, S.J. Goring, C.T. Filstrup, and E.K. Read. 2014. Creating and maintaining high-performing collaborative research teams: The importance of diversity and interpersonal skills. Frontiers in Ecology and the Environment 12(1):31-38, https://doi.org/ $10.1890 / 130001$.

Childs, J.T. Jr. 2005. Managing workforce diversity at IBM: A global HR topic that has arrived. Human Resource Management 44(1):73-77, https://doi.org/ 10.1002/hrm.20042.

Coker, J.S. 2017. Pedagogy and place in science education. Pp. 71-83 in Interdisciplinary Approaches to Pedagogy and Place-Based Education. D. Shannon and J. Galle, eds, Palgrave Macmillan, London.

Cooper, S.K., and J.C. Lewis. 2017. STEMSEAS: A vehicle for the US academic fleet to serve undergraduates from diverse backgrounds. Oceanography 30(4):146-148, https://doi.org/ 10.5670/oceanog.2017.405.

Freeman, R.B., and W. Huang. 2014. Collaboration: Strength in diversity. Nature 513:305, https://doi.org/10.1038/513305a.

Garza, C. 2021. Diversifying the ocean sciences: Thoughts on the challenge ahead. Oceanography 34(2), https://doi.org/10.5670/ oceanog.2021.204.

Gilligan, M., and S. Ebanks. 2016. The ocean science social diversity challenge. Oceanography 29(1):55-57, https://doi.org/ 10.5670/oceanog.2016.12.

Gonzales, L., and C. Keane. 2020a. Geoscience Workforce Projections 2019-2029. American Geosciences Institute, 2 pp., https://www. americangeosciences.org/geoscience-currents/ geoscience-workforce-projections-2019-2029. Gonzales, L. and C. Keane. 2020b. Diversity in the Geosciences. American Geosciences Institute, 5 pp., https://www.americangeosciences.org/ geoscience-currents/diversity-geosciences. 
Griffin, K.A. 2019. Institutional barriers, strategies, and benefits to increasing the representation of women and men of color in the professoriate. Pp. 1-73 in Higher Education: Handbook of Theory and Research, vol. 35. L. Perna, ed., Springer, https://doi.org/10.1007/978-3-030-11743-6_4-1.

Hofstra, B., V.V. Kulkarni, S.M.N. Galvez, B. He, D. Jurafsky, and D.A. McFarland. 2020. The diversity-innovation paradox in science. Proceedings of the National Academy of Sciences of the United States of America 117(17):9,284-9,291, https://doi.org/10.1073/pnas.1915378117.

Holmes, M.A., and S. O'Connell. 2005. Where are the Women Geoscience Professors? Report of a workshop held September 25-27, 2003, Washington, DC, 45 pp., https://core.ac.uk/download/ pdf/188052675.pdf.

Hurtado, S., C.B. Newman, M.C. Tran, and M.J. Chang. 2010. Improving the rate of success for underrepresented racial minorities in STEM fields: Insights from a national project. New Directions for Institutional Research 148:5-15, https://doi.org/ 10.1002/ir.357.

Johnson, A., M.J. Huggans, D. Siegfried, and L. Braxton. 2016. Strategies for increasing diversity in the ocean science workforce through mentoring. Oceanography 29(1):46-54, https://doi.org/ 10.5670/oceanog.2016.11.

Karsten, J.L. 2019. Insights from the OEDG program on broadening participation in the geosciences. Journal of Geoscience Education 67(4):287-299, https://doi.org/10.1080/10899995.2019.1565982.

Ladson-Billings, G. 1994. The Dreamkeepers: Successful Teachers of African American Children. Jossey-Bass, San Francisco, CA, 256 pp.

NAE (National Academy of Engineering). 2018. Understanding Measures of Faculty Impact and the Role of Engineering Societies: Proceedings of a Workshop. The National Academies Press, Washington, DC, 34 pp., https://doi.org/10.17226/ 25181

NAS, NAE, and IM (National Academy of Sciences, National Academy of Engineering, and Institute of Medicine). 2011. Expanding Underrepresented Minority Participation: America's Science and Technology Talent at the Crossroads. The National Academies Press, Washington, DC, 286 pp., https://doi.org/10.17226/12984.

NASEM (National Academies of Sciences, Engineering, and Medicine). 2016. Barriers and Opportunities for 2-Year and 4-Year STEM Degrees: Systemic Change to Support Students' Diverse Pathways. The National Academies Press, Washington, DC, 214 pp., https://doi.org/ 10.17226/21739.

NASEM. 2018a. The Integration of the Humanities and Arts with Sciences, Engineering, and Medicine in Higher Education: Branches from the Same Tree. The National Academies Press, Washington, DC, 282 pp., https://doi.org/10.17226/24988.

NASEM. 2018b. Sexual Harassment of Women: Climate, Culture, and Consequences in Academic Sciences, Engineering, and Medicine. The National Academies Press, Washington, DC, 312 pp., https://doi.org/10.17226/24994.

NASEM. 2019. Minority Serving Institutions: America's Underutilized Resource for Strengthening the STEM Workforce. The National Academies Press, Washington, DC, 254 pp., https://doi.org/10.17226/ 25257.

NASEM. 2020. Promising Practices for Addressing the Underrepresentation of Women in Science, Engineering, and Medicine: Opening Doors. The National Academies Press, Washington, DC, 234 pp., https://doi.org/10.17226/25585.

NRC (National Research Council). 2011. Expanding Underrepresented Minority Participation: America's Science and Technology Talent at the Crossroads. National Academies Press, Washington, DC, 286 pp., https://www.nap.edu/catalog.php?record_ $i d=12984$.
NRC. 2012. Discipline-Based Education Research: Understanding and Improving Learning in Undergraduate Science and Engineering. National Academies Press, Washington, DC, 282 pp., https://www.nap.edu/catalog.php?record_id=13362.

NRC. 2013. Seeking Solutions: Maximizing American Talent by Advancing Women of Color in Academia: Summary of a Conference. The National Academies Press, Washington, DC, 292 pp. https://doi.org/10.17226/18556.

NSB (National Science Board). 2020. Vision 2030. 24 pp., https://www.nsf.gov/nsb/publications/2020/ nsb202015.pdf.

O'Connell, S., and M.A. Holmes. 2011. Obstacles to the recruitment of minorities into the geosciences: A call to action. GSA Today 21(6)52-54,

https://www.geosociety.org/gsatoday/archive/21/6 pdf/1052-5173-21-6-52.pdf.

PCAST (The President's Council of Advisors on Science and Technology). 2020. Recommendations for Strengthening American Leadership in Industries of the Future. 46 pp., https://science.osti. gov/-/media/_/pdf/about/pcast/202006/PCAST_ June_2020_Report.pdf?la=en\&hash=019A4F17C79FDEE5005C51D3D6CAC81FB31E3ABC.

Petcovic, H.L., S.P. Turner, E. Geraghty Ward, T. Cartwright, N. LaDue, D. Mogk, A.P.K. Bentley, and X. Her. 2016. Geo-Needs: Stakeholder Needs Assessment for Broadening Participation in the Geoscience Workforce. Geo-Needs Focus Group Meetings Report, 68 pp., https://d32ogoqmya1dw8. cloudfront.net/files/geoneeds/geo-needs report.pdf.

Poulson-Ellestad, K., S. Hotaling, L.J. Falkenberg, and P. Soranno. 2020. Illuminating a black box of the peer review system: Demographics, experiences, and career benefits of associate editors. Limnology and Oceanography Bulletin 29(1):11-17, https://doi.org/10.1002/lob.10362.

Russell, S.H., M.P. Hancock, and J. McCullough. 2007. Benefits of undergraduate research experiences. Science 316:548-549, https://doi.org/10.1126/ science.1140384.

Sarkar, S., and R. Frazier. 2008. Place-based investigations and authentic inquiry. The Science Teacher 75:29-33.

Simon, S. 2002. Jackie Robinson and the Integration of Baseball. John Wiley \& Sons, 180 pp.

Smith, D.G. 2020. Diversity's Promise for Higher Education: Making It Work, $3^{\text {rd }}$ ed. Johns Hopkins University Press, Baltimore, MD, 400 pp.

Starks, B.C., and W.H. Matthaeus. 2018. STEM recruitment and beyond: The messenger is the medium. Journal of STEM Education 19(4):27-33.

Thiry, H., T.J. Weston, S.L. Laursen, and A.B. Hunter. 2012. The benefits of multi-year research experiences: Differences in novice and experienced students' reported gains from undergraduate research. CBE Life Sciences Education 11(3):201-332, https://doi.org/10.1187/ cbe.11-11-0098.

Wang, X. 2013. Why students choose STEM majors: Motivation, high school learning, and postsecondary context of support. American Educational Research Journal 50(5):1,081-1,121, https://doi.org/ 10.3102/0002831213488622.

Wilson, C. 2019. Status of the Geoscience Workforce 2018. 2019. American Geosciences Institute, Alexandria, VA, $174 \mathrm{pp}$.

Wingfield, A.H. 2020. We built a diverse academic department in 5 years. Here's how. Harvard Business Review, https://hbr.org/2020/07/webuilt-a-diverse-academic-department-in-5-yearsheres-how.

Zeigler, K., and S.A. Camarota. 2014. Is There a STEM Worker Shortage? A Look at Employment and Wages in Science, Technology, Engineering, and Math. Center for Immigration Studies, 34 pp., https://cis.org/Report/ There-STEM-Worker-Shortage.

\section{ACKNOWLEDGMENTS}

Sonya Legg's contribution is based upon work supported by the National Science Foundation (NSF) under grant no. OCE-1756633. Jonathan Lewis and Sharon Cooper have been supported by NSF Integrated and Collaborative Education and Research (ICER) award nos. 1540645, 1701168, and 1701174 . Mona Behl is supported by National Oceanic and Atmospheric Administration (NOAA) award no. NA18OAR4170084 and NSF ICER award no. 1940082. Sarah Kolesar is supported by NOAA award no. NA18OAR4170072. Lisa White is supported by NSF ICER award no. 1801752. Corey Garza is supported by NOAA Office of Education Educational Partnership Program award no. NA16SEC4810009. The authors wish to express their gratitude to two anonymous reviewers for their review of this manuscript.

\section{DISCLAIMER}

All perspectives outlined in this paper are those of the authors, and do not necessarily reflect the positions, strategies, and opinions of the National Science Foundation (NSF) or National Oceanic and Atmospheric Administration (NOAA).

\section{AUTHORS}

Mona Behl (mbehl@uga.edu) is Associate Director, Marine Extension and Georgia Sea Grant, University of Georgia, Athens, GA, USA. Sharon Cooper is Senior Staff Associate, Lamont-Doherty Earth Observatory of Columbia University, Palisades, NY, USA. Corey Garza is Professor, Department of Marine Science, and Director, Coastal and Maine Ecosystems Programs, California State University, Monterey Bay, Seaside, CA, USA. Sarah E. Kolesar is Research and Fellowship Program Leader, Oregon Sea Grant, Oregon State University, Corvallis, OR, USA. Sonya Legg is Senior Research Oceanographer and Lecturer, Princeton University, Princeton, NJ, USA. Jonathan C. Lewis is Professor, Geoscience Department, Indiana University of Pennsylvania, Indiana, PA, USA. Lisa White is Assistant Director, Education and Outreach, Museum of Paleontology, University of California at Berkeley, Berkeley, CA, USA. Brandon Jones is Program Director, Education and Diversity Programs, Directorate for Geosciences, National Science Foundation, Alexandria, VA, USA.

\section{ARTICLE CITATION}

Behl, M., S. Cooper, C. Garza, S.E. Kolesar, S. Legg, J.C. Lewis, L. White, and B. Jones. 2021. Changing the Culture of Coastal, Ocean, and Marine Sciences: Strategies for Individual and Collective Actions. Oceanography 34(3):53-60, https://doi.org/10.5670/ oceanog.2021.307.

\section{COPYRIGHT \& USAGE}

This is an open access article made available under the terms of the Creative Commons Attribution 4.0 International License (https://creativecommons.org/ licenses/by/4.0/), which permits use, sharing, adaptation, distribution, and reproduction in any medium or format as long as users cite the materials appropriately, provide a link to the Creative Commons license, and indicate the changes that were made to the original content. 